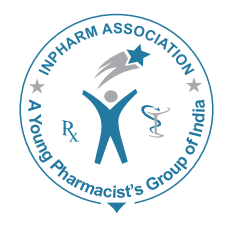

\title{
JYP
}

\section{Hospital Nuclear Pharmacy Survey: Preliminary Aspects In Brazil}

\author{
Marcelo Pau Brasil, Marcio Paes de Barros', Leila Jorge Antunes', \\ Ralph Santos-Oliveira ${ }^{1}$
}

Radiopharmacy Department, Rua Helio de Almeida, Cidade Universitária-Rio de Janeiro, Brazil, ${ }^{1}$ Nuclear Engineering Institute, Rua Helio de Almeida, Cidade Universitária-Rio de Janeiro, Brazil

Address for correspondence: Dr. Ralph Santos-Oliveira, E-mail: roliveira@ien.gov.br

\begin{abstract}
Radiopharmaceuticals are special drugs that in the composition preserve one or more radionuclides which can be used as diagnostic or therapeutic tools in Nuclear Medicine Units. This study evaluated hospitals and clinics which have nuclear medicines services at the city of Rio de Janeiro from August to November 2010. The data were obtained through a longitudinal research. The results showed that most of the hospitals $(>80 \%)$ did not have pharmacist and all them (100\%) considered that a pharmacist in the nuclear pharmacy is not required.
\end{abstract}

Key words: Nuclear medicine, nuclear pharmacy, radiopharmaceuticals, radiopharmacy

\section{INTRODUCTION}

Radioisotopes and radiopharmaceuticals for use in Nuclear Medicine constitute one of the most prominent applications of nuclear energy. ${ }^{[1]}$ Radionuclides were quickly incorporated to biologically active chemical compounds, producing a specific class of drugs known as radiopharmaceuticals. Nuclear Medicine is nowadays well established and recognized by the medical community, and the use of radiopharmaceuticals for diagnose and therapy became regular procedures. ${ }^{[2]}$

\begin{tabular}{|l|l|}
\hline \multicolumn{2}{|c|}{ Access this article online } \\
\hline Quick Response Code: & \\
\hline & Website: \\
\hline
\end{tabular}

The concept of nuclear pharmacy arose in the USA in 1960 , when for the first time were defined the services pertinent to the nuclear pharmacy or radiopharmacy, particularly the role of the radiopharmacist in the development, preparation, quality control, and dispensation of radiopharmaceuticals..$^{[2]}$ Currently, the USA, European Union, and Japan consider radiopharmacy as a regular branch of pharmacy, and the radiopharmacists as recognized members of the multidisciplinary staffs working in Nuclear Medicine. ${ }^{[3]}$ Due to the lack of specific regulation, these professionals are not yet rightfully acknowledged in Brazil.

In Brazil, radiopharmaceuticals are produced both by the public and private initiatives. Since 2006, when Constitutional Amendment 49 was passed, the production of radioisotopes by the private initiative is being steadily increasing. There are 20 cyclotron facilities in the process of being licensed, in the cities of Rio de Janeiro, São Paulo, 
Belo Horizonte, Brasília, and Salvador. The public sector contribution comes from the Comissão Nacional de Energia Nuclear (National Commission of Nuclear Energy) $\mathrm{CNEN}$ - and its research institutes. Presently, the Instituto de Engenharia Nuclear (Nuclear Engineering Institute) IEN, the Instituto de Pesquisas Energéticas Nucleares (Nuclear and Energy Research Institute) - IPEN, and the Centro de Desenvolvimento de Tecnologias Nucleares (Nuclear Technologies Development Center) - CDTN, are the country's most productive radioisotope and radiopharmaceutical centers. ${ }^{[4]}$

According to Gonçalves et al., ${ }^{\left[{ }^{[}\right]}$nuclear medicine services (hospitals, clinics, and imaging centers) throughout the country had an increasing growth following the trend of the local productive sectors. Santos-Oliveira et al. ${ }^{[6]}$ estimate that more than 3 million medical procedures using radiopharmaceuticals are performed in Brazil per year.

The aim of this study was to evaluate hospitals and clinics (hereby named hospitals) which have nuclear medicines services at the city of Rio de Janeiro from August to November 2010.

\section{METHODOLOGY}

A longitudinal research was conducted within the municipality of Rio de Janeiro from August 2010 up to November 2010, including 30 clinics/hospitals (public and private) with nuclear medicine services. Taking into account the totality of clinics and hospitals in the state of Rio de Janeiro (32), the facilities included in the research corresponded to $93.75 \%$ of all the clinics and hospitals offering nuclear medicine services in this municipality.

This study used a preprepared questionnaire (Annexure 1), covering the monthly number of patients treated at the clinics, the professionals involved in the manipulation and administration of radiopharmaceuticals, the academic qualification of the Radioprotection Supervisors, of those in charge of the radiopharmaceuticals manipulation, and the existence of secondary and elementary educational level personnel in the staff, among other informations.

\section{RESULTS AND DISCUSSION}

In terms of the number of people using radiopharmaceuticals, the results show a very strong demand for these substances, mainly in diagnostics, as shown in Table 1.

In terms of professionals acting as Radioprotection Supervisors, the study showed that $53 \%$ of them are physicists, $41 \%$ are physicians, and only $6 \%$ are pharmacists [Figure 1].
The results revealed that regarding the professionals responsible for manipulating the radiopharmaceuticals, just only $10 \%$ were made by pharmacists [Figure 2].

Although the manipulation of drugs (as radiopharmaceuticals) and their derivatives is private from pharmacists the study showed that this activity is developed mainly by physicians $(30 \%)$ and biologists $(60 \%)$. This fact is alarming and imposes an urgent paradigm shift. Although they may be very capable, both physicians and biologists do not have suitable academic skills (education). Nevertheless, this act practiced by nonpharmacists may interpret as illegal with severe consequences.

The results concerned about the dose calculating of radiopharmaceuticals are shown in Figure 3.

Though this practice is not private of pharmacist the dose calculating is intrinsically linked to the quality control as the manipulation of radiopharmaceuticals and for that should be supervised by a pharmacist.

The results showed that both physicians and biologist have their importance well established in a hospital nuclear pharmacy (hospital radiopharmacy) in a multidisciplinary team. However the same cannot be said by the pharmacists, which as observed, in most of the cases, are even included in the team.

The answers collected from the questionnaire also revealed that from all hospitals studied $100 \%$ of the nuclear

Table 1: Number of patients using adiopharmaceuticals

\begin{tabular}{lc}
\hline Indication & Number of patients per month \\
\hline Diagnosis & 5738 \\
Therapy & 74
\end{tabular}

Therapy 74

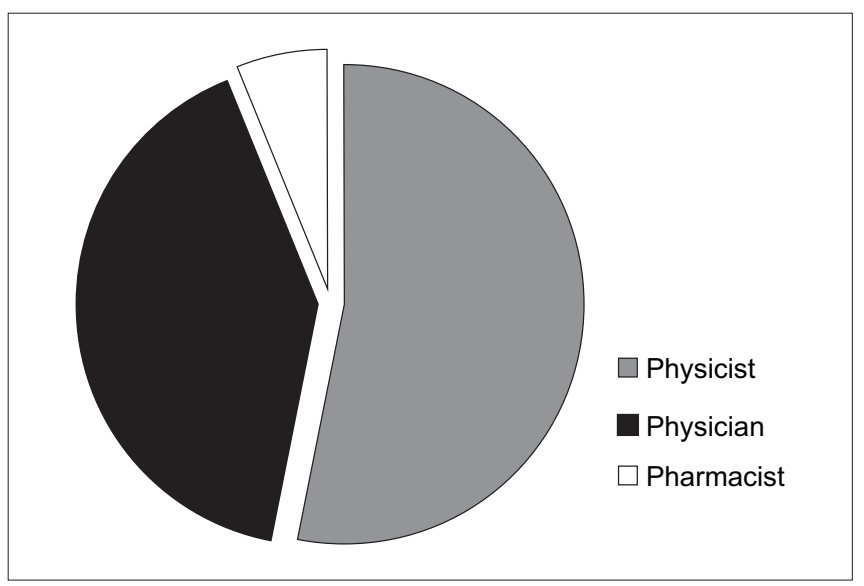

Figure 1: Distribution of responsible for nuclear pharmacy in all hospital analyzed by this study 


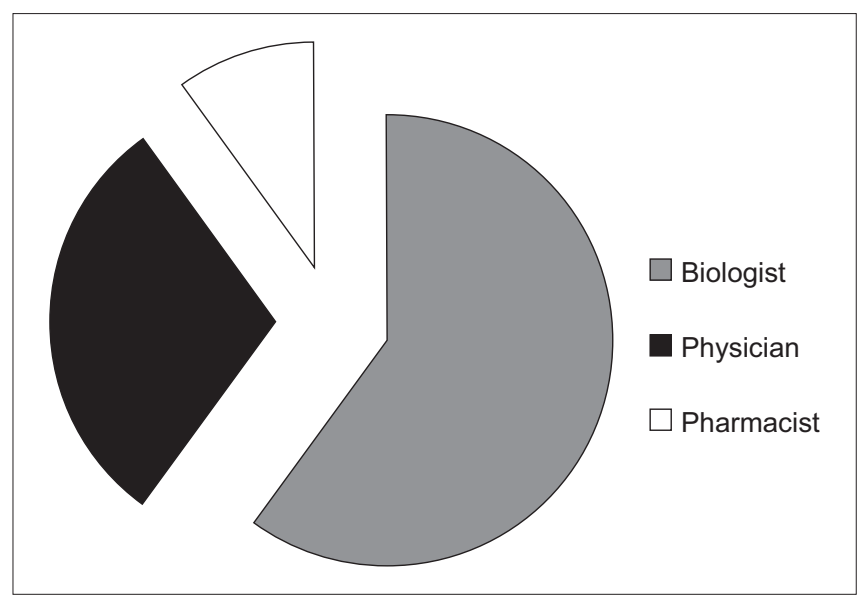

Figure 2: Distribution of professionals responsible by the manipulation and quality control of radiopharmaceuticals in the hospitals analyzed during the study

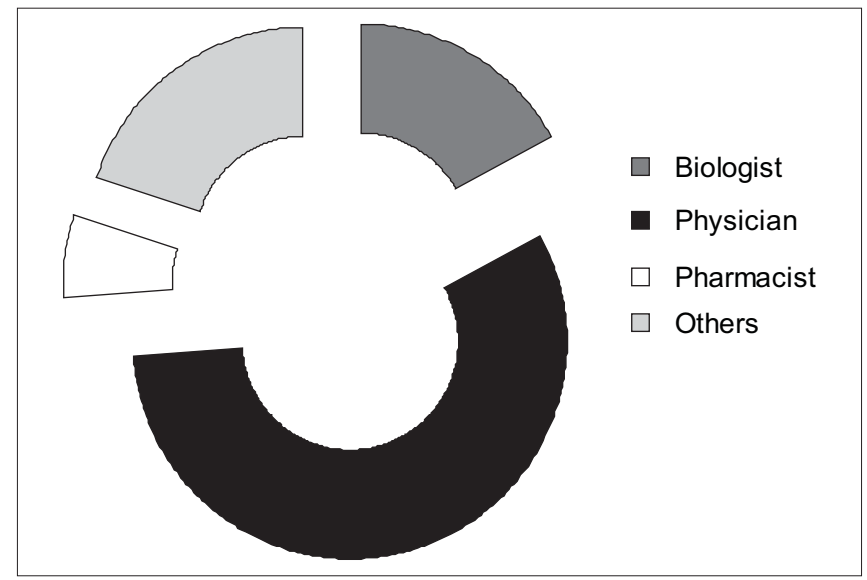

Figure 3: Distribution of professionals responsible for the dose calculating in the the hospitals analyzed in this study

medicine services considered that keep a pharmacist is not essential and would raise the cost for the hospitals.
Also, the research found that the dose administrations of radiopharmaceuticals were made by the nursing technician without any specific training in the nuclear pharmacy field.

\section{CONCLUSION}

The results demonstrated that a paradigm shift should be made urgently in nuclear pharmacies around the Rio de Janeiro and Brazil. The concept of hospital nuclear pharmacy without a pharmacist is absolutely wrong and may cause damages to the patient. In this case a more specific legal instrument is required. Indeed an action from the Surveillance System of Brazil integrated with the Federal Council of Pharmacy is necessary in order to avoid this type of practice.

\section{REFERENCES}

1. Santos-Oliveira R, Machado M. Pitfalls with radiopharmaceuticals. Am J Med Sci 2011;342:50-3.

2. Santos-Oliveira R, Smith SW, Carneiro-Leão AM. Radiopharmaceuticals drug interactions: A critical review. An Acad Bras Cienc 2008;80:665-75.

3. Santos-Oliveira R, Smith SW. Radiopharmacy in Brazil after Amendment 49. Int J Nucl Law 2008;2:115-20.

4. Santos-Oliveira R. Regulamentação de radiofármaco: União européia, estados unidos e Brasil. LAJP 2008;27:906-8.

5. Gonçalves OD, Assis AS, Filho AT, Dias AF. Relatório de Gestão 2007. 198 pp. CNEN, Rio de Janeiro, 2006. Available from: http://www.cnen. gov.br/acnen/relatorios/rel-gestao-2006.pdf.

6. Santos-Oliveira R, Smith SW, de Souza Albernaz M, Bordim JA, Antunes LJ.Surveillance of radiopharmaceuticals in Latin American: An alert. Rev Esp Med Nucl 2011;30:134-6.

How to cite this article: Brasil MP, de Barros MP, Antunes LJ, Santos-Oliveira R. Hospital nuclear pharmacy survey: Preliminary aspects in Brazil. J Young Pharmacists 2012;4:279-81.

Source of Support: CNPq, FAPERJ, Conflict of Interest: None declared. 